\title{
Time management as a main factor influencing outpatients satisfaction on quality of service in public health facilities
}

\author{
Abner Kukeyinge Shopati ${ }^{1 *}$, Kabwebwe Honore Mitonga ${ }^{2}$, Anna Shilunga ${ }^{3}$ \\ ${ }^{1}$ University of Namibia, Business School \\ ${ }^{2}$ University of Namibia, School of Public health \\ ${ }^{3}$ University of Namibia, School of Nursing \\ *Corresponding author E-mail: shopati.abner@gmail.com
}

\begin{abstract}
This study aims to explore factors influencing outpatient client satisfaction level with quality of service to recommend friends and family to the three intermediate public health hospitals in Namibia. Reviewing the literature, 14 variables were identified. The items were then reduced using exploratory factor analysis which is evaluated using Principal Axis Factoring with Direct Oblimin rotation. Using exploratory factor analysis, variables were categorized into 8 factors. This model, in the order of effect, identified Total Time Spent in the outpatient department before leaving (in minutes) is the most important predictor of ES (expected satisfaction) values of (0.499), Sum of Medication Communication (0.105), Contact Time with Doctors/Nurses (in minutes) (0.099), Sum of Nurse Communication (0.089), Sum of Doctor Communication (0.049), First Time Visit to this Outpatient Department (0.031), Age groups (0.030) and Facility Name (0.011) is the least important predictor for client to recommend their friends and family to the three intermediate public health care in Namibia. This implies that Total Time Spent in the outpatient department before leaving (in minutes) is the most important predictor of ES by outpatient clients on quality of service perceptions and has the largest impact of recommending friends and family to receive services at the three intermediate public hospitals.
\end{abstract}

Keywords: Time Management; Quality of Service; Outpatient Client; Namibia, Level of Satisfaction.

\section{Introduction}

According to Murante (2010), frequently, the word patient, user and consumer are indistinguishably used as substitutes while they vary for the nature of relationships between health professionals and citizens. Whereas the patient is a person who has an illness and comes to doctors and nurses asking for information and treatment; the user may identify people who used, use or could use health care services. Alternatively, Murante (2010) citing Herxheimer and Goodare (1999) argues that the word consumer can be attributed to a person who buys goods and services for his needs or a person who consumes something, thus it bears the commercial connotation then This connotation has changed since the introduction of customer service-oriented culture in both public and private health care system as client orientation service delivery become a focal point for all health care providers. While Shackley and Ryan (1994) noted that the patient becomes a consumer when he/she looks for health services after having collected all information helpful to make the best choice. Therefore, in this study, the words patient and customer/client are used to mean the same above. Thus, the important questions of this study are: What are the factors contributing to outpatient satisfaction with the quality of services at the three intermediate public health hospitals in Namibia? Which factor is mostly described as the main predictor for outpatient clients' satisfaction with quality of services at the three intermediate public health hospitals to recommend to their family and friends?

\section{Literature reviews}

\subsection{Patient satisfaction: a multifaceted concept}

According to Murante (2010), researchers, health policy-makers and managers used to pay more attention to the patient perception of the quality of health services but nowadays the focus is on "patient satisfaction" or "customer satisfaction of the service quality provided. The patient satisfaction concept was initially thought to be a problematic concept to be measured and interpreted by researchers and health care providers because of its multidimensional and subjective nature which is affected by individuals' expectations, needs or desires. This dilemma could hold water till today as individuals are qualitatively different and their demographic origin could play a role in expecting and/or rating quality of service provided. As such, Murante (2010) argues that the factors influencing dissatisfaction could be somewhat different from factors generating satisfaction. When users have limited knowledge of opportunities and low expectations of quality of service, then high satisfaction scores may be recorded even though poor standards of care have been ensured (Murante, 2010).

Jenkinson et al. (2002) posits that patient satisfaction rating on quality of service can still be used by rating scale as results with this method could be considered more helpful in order to identify weaknesses in the delivery and organization of health services. For example, patients' willingness to use again and/or recommend services (e.g., hospital, general practitioner, etc.) is explored as a reliable proxy of overall evaluation of service quality. 
Murante (2010) found that numerous studies show that patient satisfaction measurement in terms of expectations, health status, socioeconomic and demographic characteristics, and also of service are indicative of patient expectations, but do not totally explain satisfaction with service. The main criticism towards patient satisfaction indicators is about the fairness of comparison since patients' ratings reflect subjective factors such as:

- Their personal preferences and expectations, and

- The realities of care received (Woodbury et al, 1998).

These factors are strongly correlated to patient socio-demographic characteristics, patient experiences with health services and organizational and environmental features of context where care is provided. However, the expectations positively influence patients' satisfaction and when the self-reported health status is poor, dissatisfaction with organizational quality of care increases. Additionally, Murante (2010) found that a positive relationship between age and satisfaction exists while a high education negatively affects satisfaction rates and that nurses and physician's assistance is a predictor of satisfaction more than the quality of food and the cleanliness of rooms.

Seghieri et al. (2009) claims that a doctor's role in patient assistance affects largely the overall evaluation of hospital service regardless of the three patients' groups: particularly, patient's evaluation is explained by how doctors and nurses work together and by doctors' care. Team work is a fundamental element of new organizational models for all health services: it could have positive effects both on patient experience, and on professionals' satisfaction (Murante, 2010). From the professionals' perspective, it was observed that predictor's satisfaction with inter-professional co-operation can be different for nurse and doctor; thus it is not correct to believe that the team work is equally appreciated and understood by both professions (Seghieri et al., 2009). For this reason it is important to focus on cultural changes in order to improve hospital quality. Firstly, having the same goals for the same patient has to become the starting point for building a team of professionals. Using a common language and sharing information and clinical protocols have benefits for professionals and mostly for the patient. Also, doctors' and nurses' interpersonal skills may affect their relationship with patients.

Sitzia and Wood (1997) noted that the communication process during consultation with client has a potential to influence the patient experience so greatly to affect the patient's willingness to recommend hospitals to friends or family members; thus it is a crucial predictor. Murante (2010) states that "an appropriate and focused communication strategy should be useful to respond to these needs and to promote the patient's empowerment and participation. In this way, the patient could have an active role in the decision-making process and become responsible for his care pathway" (p. 15).
Outpatient Health Care (O-PAHC) questionnaire was used as an implementation evaluation tool focusing on the patient satisfaction with public health care delivery. The O-PAHC questionnaire is an effective tool to measure the impact of the failure to implementation strategic decisions on client satisfaction and quality of service perceptions at the three intermediate public hospitals in Namibia. The O-PAHC questionnaires covered eight domains with impact on client satisfaction with quality of service: Sum of Nurse Communication, Sum of Doctor Communication, Sum of Medication Communication, Total Time Spent in the outpatient deparment before leaving (in minutes), Contact Time with Doctor/Nurses (in minutes), First Time Visit to this Outpatient Department, Age Groups and Facility Name. However, items asking patients to provide an overall evaluation of care and asking patients if they would recommend this facility to friends and family were added to test whether clients are being satisfied with the quality of service provided by the three intermediate public health care. Respondents were asked to rate quality of service indicators of the Outpatient Hospital facility they visited using the Likert scale. The scale allowed them to strongly agree/agree or strongly disagree/disagree with a statement about their experiences at the public health facility.

LIBQUAL model was used to assess O-PAHC client minimum level of service expectation and maximuml level of service desired.

\subsection{Sample and data collection}

This study covered three intermediate public health care in Namibia. Proportional Stratified sampling was employed and clients were systematic randomly selected. The total sample size for the clients is 2,366 which include Rundu Intermediate State Hospital (RISH) with 540 clients, Katutura Intermediate State Hospital (KISH) with 760 clients and Oshakati Intermediate State Hospital (OISH) with 1067 clients. The questionnaire response rate is good at 93 percent for the clients, which resulted in 2190 usable questionnaires for the clients. The research period was limited to April 2016 - May 2016.

\section{Data analysis}

\subsection{Result presentation}

The final questionnaire was distributed among clients. Data analysis was performed by SPSS 23 software. The questionnaire assessed the total time taken in the outpatient department, time taken waiting to be served and the contact time with the nurses and doctors. Table 6.8 presents the results for the time management and the mean values of the summation of communication.

\section{Research methodology}

\subsection{Questionnaire construct}

Table 1: Time Management during the Visit

\begin{tabular}{|c|c|c|c|c|c|c|c|c|c|c|}
\hline \multirow{2}{*}{ Variable } & \multicolumn{2}{|c|}{$\begin{array}{l}\text { Oshakati } \\
(\mathrm{N}=980)\end{array}$} & \multicolumn{2}{|c|}{$\begin{array}{c}\text { Rundu } \\
(\mathrm{N}=500)\end{array}$} & \multicolumn{2}{|c|}{$\begin{array}{l}\text { Katutura } \\
(\mathrm{N}=710)\end{array}$} & \multicolumn{4}{|c|}{ Total $(\mathrm{N}=2190)$} \\
\hline & Mean & S.D & Mean & S.D & Mean & S.D & Mean & S.D & Skewness & Kurtosis \\
\hline Sum of Doctor Communication & 19,34 & 5,10 & 17,35 & 4,61 & 17,28 & 4,95 & 18,22 & 5,04 & $-0,29$ & $-1,01$ \\
\hline Sum of Nurse Communication & 13,64 & 5,25 & 13,13 & 4,54 & 12,46 & 4,65 & 13,14 & 4,93 & $-0,29$ & $-1,15$ \\
\hline Sum of Medication Communication & 9,24 & 1,56 & 9,57 & 1,09 & 9,76 & 1,28 & 9,49 & 1,40 & $-0,91$ & 0,07 \\
\hline $\begin{array}{l}\text { Time taken before nurses and doctors } \\
\text { attended to patient (in minutes) }\end{array}$ & 148 & 39 & 101 & 31 & 126 & 35 & 130 & 37 & $-0,12$ & $-1,30$ \\
\hline $\begin{array}{l}\text { Total time spent in the outpatient } \\
\text { before leaving (in minutes) }\end{array}$ & 233 & 72 & 228 & 55 & 230 & 56 & 231 & 63 & $-0,95$ & 0,11 \\
\hline $\begin{array}{l}\text { Contact Time with Doctors/Nurses } \\
\text { (in minutes) }\end{array}$ & 167 & 38 & 237 & 64 & 210 & 60 & 197 & 60 & 0,65 & $-0,08$ \\
\hline
\end{tabular}


Table 1: shows that it takes an average 148 minutes before nurses and doctors can attend a patient at OISH, while it takes 101 minutes at RISH and 126 minutes at KISH. However, the total time spent in the outpatient department before exit is nearly the same in all hospitals at an average 231 minutes overall. RISH patients enjoy the most contact time with doctors and nurses at 237 minutes, followed by KISH at 210 minutes and the OISH with 167 minutes, resulting in an overall average of 197 minutes contact time in outpatient.

The communication section questions are added up to give a single communication factor that is used to further understand the relationship or any association which may exist between the way the hospital staff communicate and the contact time with the patients. Understanding this association will help quantifying the impact of strategic decision implementation on client satisfaction and quality of service perceptions of the Namibian public health care system. Table 6.8 shows that OISH has better communication with patients for both doctors $(M=19.34, S . D=5.10)$ and nurses $(M=13.64$, S.D=5.25), even though it has the minimum contact time with patients. While, RISH and KISH are comparable in their levels of communication. However, KISH has better medication communication (M=9.76, S.D=1.28) than the other two hospitals, with RISH $(\mathrm{M}=9.57, \mathrm{~S} . \mathrm{D}=1.09)$ better than OISH $(\mathrm{M}=9.24, \mathrm{~S} . \mathrm{D}=1.56)$.

\section{Correlation analysis}

The study used the Pearson correlation coefficient to explore bivariate association between the factors in preparation of regression analysis. Table 2 shows relational effects ranging from -0.02 to 0.803 with a significance level varying $(p<.05, p<.01)$.

Table 2: Correlational Matrix

\begin{tabular}{|c|c|c|c|c|c|c|c|c|c|c|c|c|c|c|}
\hline & & 1 & 2 & 3 & 4 & 5 & 6 & 7 & 8 & 9 & 10 & 11 & 12 & 13 \\
\hline 1 & Age of the patient & 1 & & & & & & & & & & & & \\
\hline 2 & Facility_Name & $-.180^{* *}$ & 1 & & & & & & & & & & & \\
\hline 3 & $\begin{array}{l}\text { Time taken before nurses and doctors attended to } \\
\text { patient (in minutes) }\end{array}$ &, 000 & $-.128^{* *}$ & 1 & & & & & & & & & & \\
\hline 4 & $\begin{array}{l}\text { Total time spent in the outpatient before leaving (in } \\
\text { minutes) }\end{array}$ & $-.094^{* *}$ &,- 023 & $.692^{* *}$ & 1 & & & & & & & & & \\
\hline 5 & Contact Time with Doctors/Nurses (in minutes) & $-.099^{* *}$ & $.224^{* *}$ & $-.302^{* *}$ & $.295^{* *}$ & 1 & & & & & & & & \\
\hline 6 & Did you have to pay for this visit? & $.321^{* *}$ & $-.209^{* *}$ & $-.103^{* *}$ & $-.169^{* *}$ & $-.102^{* *}$ & $\mathbf{1}$ & & & & & & & \\
\hline 7 & Did you regard this payment expensive? & $.279^{* *}$ & $-.168^{* *}$ & $-.066^{* *}$ & $-.079^{* *}$ & $-.045^{*}$ & $.142^{* *}$ & 1 & & & & & & \\
\hline 8 & Affordability of service & $.395^{* *}$ & $-.247^{* *}$ & $-.111^{* * *}$ & $-.159^{* *}$ & $-.093^{* *}$ & $.701^{* * *}$ & $.803^{* *}$ & $\mathbf{1}$ & & & & & \\
\hline 9 & Sum of Doctor Communication & $.075^{* *}$ & $-.184^{* *}$ & $-.100^{* * *}$ & $-.180^{* *}$ & $-.090^{* *}$ & $.050^{*}$ & $.060^{* *}$ & $.071^{* * *}$ & 1 & & & & \\
\hline 10 & Sum of Nurse Communication & $.093^{* *}$ & $-.104^{* *}$ & $-.256^{* *}$ & $-.296^{* *}$ &,- 029 & $.195^{* *}$ & $.117^{* *}$ & $.201^{* *}$ & $.602^{* *}$ & $\mathbf{1}$ & & & \\
\hline 11 & Sum of Medication Communication &,- 030 & $.164^{* *}$ & $.271^{* *}$ & $.310^{* *}$ & $.061^{* *}$ & $-.177^{* *}$ & $.053^{*}$ & $-.071^{* *}$ & $-.212^{* *}$ & $-.238^{* *}$ & 1 & & \\
\hline 12 & $\begin{array}{l}\text { Would you recommend this outpatient department to } \\
\text { your friend and family? }\end{array}$ & $-.154^{* *}$ & $.068^{* *}$ & $.387^{* *}$ & $.412^{* *}$ &,- 019 & $-.146^{* *}$ & $-.198^{* *}$ & $-.231^{* *}$ & $-.298^{* * *}$ & $-.374^{* * *}$ & $.308^{* *}$ & 1 & \\
\hline 13 & $\begin{array}{l}\text { Is this your first time to visit this outpatient } \\
\text { department? }\end{array}$ &, 006 & $.110^{* *}$ &,- 010 &, 030 & $.094^{* *}$ & $-.089^{* *}$ & $.083^{* *}$ & ,003 &,- 039 &,- 025 & $.523^{* *}$ & $.045^{*}$ & 1 \\
\hline 14 & Did you receive all the medication prescribed? & 028 & $-.118^{* *}$ & $.307^{* *}$ & $.246^{* *}$ & $-.124^{* *}$ & $-.075^{* *}$ & $.072^{* *}$ & ,004 & $-.048^{*}$ & $-.145^{* *}$ & $.523^{* *}$ & $.236^{* *}$ & $.136^{* *}$ \\
\hline
\end{tabular}

Note. Significance level set at $* \mathrm{p}<.05 ; * * \mathrm{p}<.01 ; \mathrm{N}=2190$ with pair wise deletion of missing data.

The overall satisfaction of the service provided by the three hospitals is measured using the question: 'Would you recommend this outpatient department to your friends and family?' If the patient answers yes, then it would imply that they are happy with the service. In addition, time management, communication and affordability of the service are also used as proxy variables of the impact of strategic decision implementation on client satisfaction and quality of service perceptions of the Namibian public health care system. Table 6.9 presents the Pearson correlation analysis results of the association between these proxy variables. The results show that most of the relationships are statistically significant; this is due to the large sample size of 2190. As such, the focus will only be on the magnitude of the correlational coefficients and those with values above 0.3 are considered.

The results show the affordability of service variable which is a dummy variable created by multiplying the 'Did you have to pay for this visit?' ( $\mathrm{r}=0.701$ ) and the 'Did you regard this payment expensive?' ( $\mathrm{r}=0.803)$. The results show that the older patients are more likely to pay for the visit compare to the young ones $(\mathrm{r}=0.321)$. The results also show that the time taken in the outpatient department has a mild positive relationship with recommending the outpatient department to friends and family $(\mathrm{r}=0.412)$. The lesser the time spent at the outpatient department, the more the patients recommending the outpatient department to their family and friends. Table 6.8 also shows that improved communication by Doctors ( $\mathrm{r}$ $=-0.298)$, Nurses $(r=-0.374)$ and Medication $(r=-0.308)$ will result in improved satisfaction of the patients making them willing to recommend the outpatient department to their family and friends. The results show that first time patients or those who cannot remember if it is their first time ( $\mathrm{r}=0.523)$, are more likely to recommend the outpatient department to their friends and family. The same is true for those who received all the prescribed medication $(\mathrm{r}=0.523)$.

\subsection{Regression Analysis}

This section presents findings of the regression analysis of the impact of strategic decision implementation on client satisfaction and quality of service perceptions of the Namibian public health care system, based on the three intermediate public hospitals in KISH, OISH and RISH. A forward stepwise multiple linear regression model is used to explore the relationship between recommending the outpatient department to friends and family and the proxy variables. Figure 6.1 presents the model summary.

The Patient Satisfaction model (Figure 6.1) has an accuracy of 32.1 percent (Adjusted $\mathrm{R}^{2}=0.321$ ), which means it explains only 32.1 percent of the total variability. Table 3 presents the variables of the importance to the prediction of patient satisfaction and the likelihood of recommending the outpatient department to friends and family. Total time spent in the outpatient department before leaving explains 49.9 percent of the variability of patient satisfaction. This is followed by Communication aspects of medication (10.5\%), contact time with Doctors/Nurses (9.9\%), Nurses (8.9\%), and Doctors $(4.9 \%)$. 


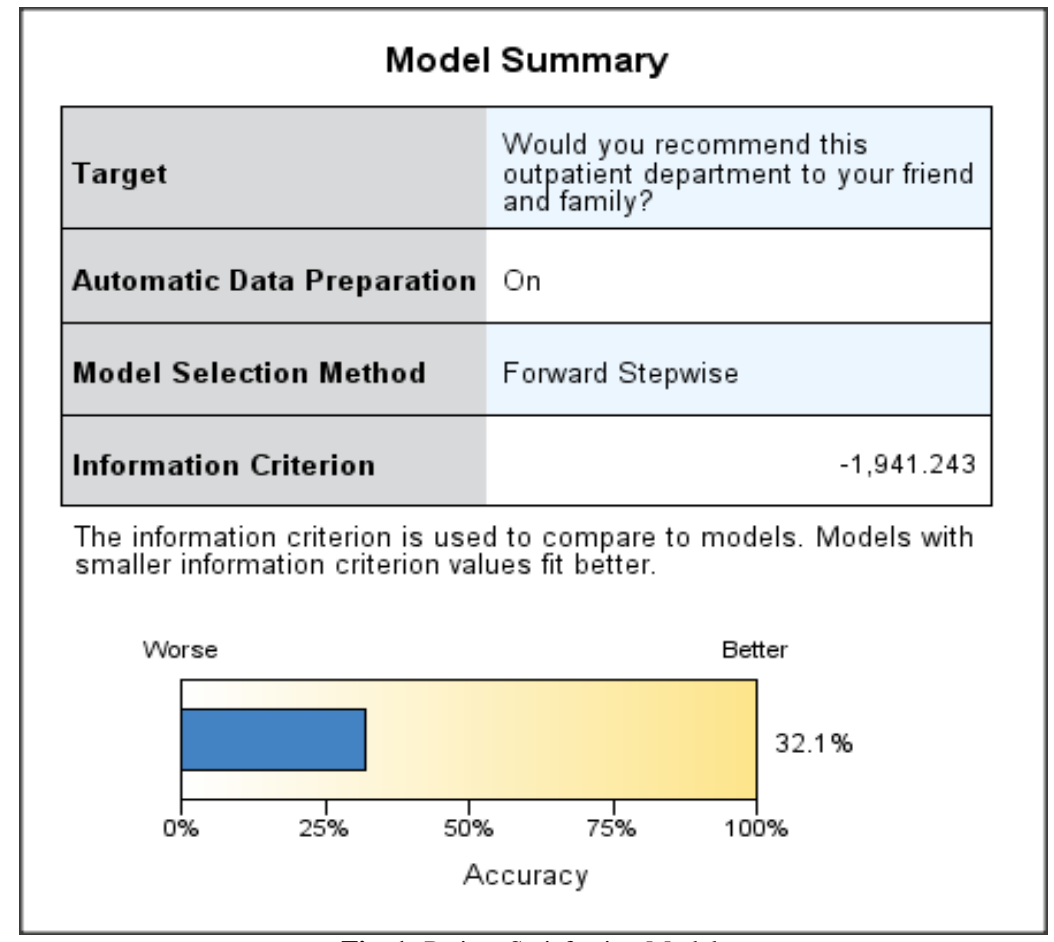

Fig. 1: Patient Satisfaction Model.

Table 3: Predictor Importance for Patient Satisfaction Model

\begin{tabular}{ll}
\hline Predictor & Importance \\
\hline Total time spent in the outpatient before leaving (in minutes) & 0.499 \\
Sum of Medication Communication & 0.105 \\
Contact Time with Doctors/Nurses (in minutes) & 0.099 \\
Sum of Nurse Communication & 0.089 \\
Sum of Doctor Communication & 0.049 \\
First time to visit this outpatient department? & 0.031 \\
Age groups & 0.030 \\
Facility name & 0.011 \\
\hline
\end{tabular}

This model, in the order of effect, identified Total Time Spent in the outpatient before leaving (in minutes) is the most important predictor of ES (expected satisfaction) values of (0.499), Sum of Medication Communication (0.105), Contact Time with Doctors/Nurses (in minutes) (0.099), Sum of Nurse Communication (0.089), Sum of Doctor Communication (0.049), First Time Visit to this Outpatient Department (0.031), Age groups (0.030) and Facility Name (0.011) is the least important predictor for client to recommend their friends and family to the three intermediate public health care in Namibia.

\section{Conclusion}

Health care providers shall be aware that patient satisfaction concept is a multidimensional and subjective in nature which is affected by individuals' expectations, needs or desires. Such an understanding of this phenomenon could be attributed by the fact that individuals are qualitatively different and their demographic origin could play a role in expecting and/or rating quality of service provided Therefore, from the perspective of patient care centred approach, public health managers shall recognise that patients play a more independent role in the health care decision-making process, in knowing more information about their health and service available to them, having equitable access and freedom of choice, getting prompt attention, respect and quality of services provided. In reviewing literature, 14 variables were identified. The items were then reduced with exploratory factor analysis which is evaluated using Principal Axis Factoring with Direct Oblimin rotation. Using exploratory factor analysis, variables were categorized into 8 factors. This model, in the order of effect, identified that Total Time Spent in the Outpatient department before leaving (in minutes) is the most important predictor of ES (expected satisfaction) values of (0.499), Sum of Medication Communication (0.105), Contact time with Doctors/Nurses (in minutes) (0.099), Sum of Nurse Communication (0.089), Sum of Doctor Communication (0.049), First Time Visit to this Outpatient Department (0.031), Age groups $(0.030)$ and Facility Name (0.011) is the least important predictor for clients to recommend their friends and family to the three intermediate public health care in Namibia. This implies that Total Time Spent in the outpatient before leaving (in minutes) is the most important predictor of ES by outpatient clients on quality of service perceptions and has the largest impact of recommending friends and family to receive services at the three intermediate public hospitals. Thus, Health Care Systems need to move away from the idea of patients as passive and dependent stakeholders. As a result, this research considers patients as internal stakeholders to the successful implementation of the strategic plan.

\section{Funding}

This work was supported by a grant from the National Commission on Research, Science and Technology (NCRST) Namibia, 2016.

\section{References}

[1] Alexander, L. D. (1991). Strategy implementation: nature of the problem". (D. Hussey, Ed.) International Review of Strategic Management, 2(1), 73-96.

[2] Alotaibi, Y., \& Liu, F. (2016). Business process modelling framework derive and implement IT goals: a case study. Int. J. Industrial and Systems Engineering, 22(2), 161-190. https://doi.org/10.1504/IJISE.2016.073961.

[3] Card, D., Dobkin, C., \& Maestas, N. (2009). Does Medicare Save Lives? Quarterly Journal of Economics, 597-636. https://doi.org/10.1162/qjec.2009.124.2.597. 
[4] Chawla, M., \& Govindaraj, R. (1996). Improving Hospital Performance through Policies to Increase Hospital Autonomy: Implementation Guidelines. Health Care Financing and Private Sector Development portfolio, AFR/SD/Health and Human Resources for Africa (HHRAA) Project. Washington: USAID/.

[5] Clark, C. E. (1962). A Pert Model for the distribution of an activity. Operations Research, 405-406. https://doi.org/10.1287/opre.10.3.405.

[6] Clements, B., Coady, D., \& Gupta, S. (2012). The economics of public health care reform in advanced and emerging economies. In B Clements, D. Coady, \& S. Gupta, The economics of public health care reform in advanced and emerging economies (pp. 3-23). Washington D.C: IMF.

[7] David, F. R. (2011). Strategic management: concepts and cases (13th ed.). New Jersey: Prentice Hall.

[8] De Vos, A. S., Strydom, H., Fouche, C. B., \& Delport, C. S. (2011) Research at grass roots: For the social sciences and human service professions. (4th ed.). Pretoria: Van Schaik Publishers.

[9] Hair, J. F., Black, W. C., Babin, B. J., Anderson, R. E., \& Tatham, R. L. (2013). Multivariate Data Analysis (7th ed.). USA: Pearson Prentice Hall.

[10] Hernon, P. (2002). Quality: New directions in the research. The Journal of Academic Librarianship, 28, 224-231. https://doi.org/10.1016/S0099-1333(02)00286-0.

[11] Jakab, M. (2007). An Empirical Evaluation of the Kyrgyz Health Reform: Does It Work for the Poor? Harvard School of Public Health, Department of Health Policy and Management. Cambridge, MA: Harvard University.

[12] Joumard, I., Andre, C., \& Nicq, C. (2010). Health Care Systems: Efficiency and Institutions. Economics Department Working Paper No. 769. Paris: Organization for Economic Cooperation and Development. https://doi.org/10.1787/5kmfp51f5f9t-en

[13] Kathora, H., \& Strauss, E. (2012). A follow-up report of the AuditorGeneral on performance audit study on MoHSS- referral system for the financial years 2008, 2009 and 2010. Windhoek: Office of the Auditor-General.

[14] Kline, P. (1994). An Easy Guide For Factor Analysis. New York, USA: Routledge.

[15] Kobus, M. (2013). First Steps in Research (13th ed.). Pretoria: Van Schaik Publisher.

[16] Latif, B., Gohar, F. R., Hussain, A., \& Kashif, M. M. (2013). Barriers to Effective Strategic Planning. International Journal of Management \& Organizational Studies, 1(2), 16-21.

[17] Lau, A. T. (1999). Making sense of contemporary strategic implementation: towards a conceptual model. Public Administration \& Management: An Interactive Journal, 4(4), 494-507.

[18] Leedy, P. D., \& Ormrod, J. E. (2010). Practice Research: Planning and Design. New York: Pearson.

[19] Lega, F., Longo, F., \& Andrea, R. (2013). Decoupling the use and meaning of strategic plans in public healthcare. BMC Health Services Research, 13(5). Retrieved October 28, 2015, from http://www.biomedcentral.com/1472-6963/13/5 https://doi.org/10.1186/1472-6963-13-5.

[20] Low, A., de Coeyere, D., Shivute, N., \& Brandt, L. (2001). Patien referral patterns in Namibia: identification of potential to improve the efficiency of the health care system. International Journal of Health Planning and Management, 16. https://doi.org/10.1002/hpm.628.

[21] Mahadevan, B. (2007). Operations Management: Theory \& Practice. London: Pearson Education.

[22] Marcinko, D. E., \& Hetico, H. R. (2014). Financial Managemen Strategies for Hospitals and Healthcare Organizations: Tools, Techniques, Checklists and Case Studies. Boca Raton, FL: CRC Press.

[23] Meyer, V., Pascucci, L., \& Murphy, J. P. (2012, May). Implementing Strategies in Complex Systems: Lessons from Brazilian Hospitals. BAR, (Special Issue, art. 2), 19-37.

[24] MoHSS. (2000). Demographic and Health Survey. Windhoek: Ministry of Health and Social Services.

[25] MoHSS. (2007). Demographic and Health Survey. Windhoek: Ministry of Health and Social Services.

[26] MoHSS. (2008). Health and Social Services System Review. Windhoek: Ministry of Health and Social Services.

[27] MoHSS. (2009). 2009 - 2013 Strategic Plan. Windhoek: Ministry of Health and Social Services.

[28] MoHSS. (2010). National Health Policy Framework 2010-2020 Windhoek: Ministry of Health and Social Services. Retrieved from http://www.healthnet.org.na

[29] MoHSS. (2013a). National Referral Policy. Windhoek: Ministry of Health and Social Services.
[30] MoHSS. (2014a). Report of the National HIV Sentinel Survey. Windhoek, Namibia: Ministry of Health and Social Services.

[31] MoHSS. (2014b). Namibia Child Survival Strategy 2014-2018. Windhoek: Ministry of Health and Social Services.

[32] MoHSS. (2015, June). Namibia 2012/13 Health Accounts Report. Windhoek, Namibia: Ministry of Health and Social Services.

[33] MoHSS/NSA. (2013). Namibia Demographic and Health Survey. Windhoek: Ministry of Health and Social Services/Namibia Statistics Agency.

[34] MoHSS-ICF. (2011, February). Health Facility Census (HFC) 2009 Windhoek: Ministry of Health and Social Services (MoHSS) and ICF Macro.

[35] Murante, A. M. (2010). Patient satisfaction: a strategic tool for health services management. Doctor of Philosophy Thesis. Scuola Superiore Sant'Anna.

[36] Nowicki, M. (2004). The financial management of hospitals and healthcare organizations. Chicago: Health Administration Press.

[37] NSA. (2012). Namibia 2011 Population and Housing Census. Windhoek: Namibia Statistics Agency (NSA).

[38] Office of the President. (2013). Presidential Commission of Inquiry on Health and Social Services. Windhoek: Government Printer.

[39] Pallant, J. (2010). SPSS survival manual: A step by step guide to data analysis using SPSS. England: Open University Press.

[40] Parasuraman, A., Berry, L. L., \& Zeithaml, V. A. (1991). Refinement and reassessment of the SERVQUAL Scale. Journal of Retailing, 67, 420-450.

[41] Parasuraman, A., Zeithaml, V. A., \& Berry, L. L. (1985). A conceptual model of service quality and its implications for future research. Journal of Marketing, 49(4), 41-50. https://doi.org/10.2307/1251430.

[42] Pleguezuelo, R. H., Pérez, J. G., \& Rambaud, S. C. (2003, January). A note on the reasonableness of PERT hypotheses. Operations Research Letters, 31(1), pp. 60-62. Retrieved from http://dx.doi.org/10.1016/S0167-6377(02).

[43] Pomp, M., \& Vujic, S. (2008). Rising Health Spending, New Medical Technology, and the Baumol Effect. Discussion Paper No. 115. The Hague: Netherlands Bureau for Economic Policy Analysis.

[44] Reyes-Alcázar, V., Torres-Olivera, A., Núñez-García, D., \& Almuedo-Paz, A. (2012). Critical Success Factors for Quality Assurance in Healthcare Organizations. In M. Savsar, Quality Assurance and Management (pp. 267-289). Rijeka, Croatia: InTech Europe. Retrieved August 20, 2015, from http://www.intechopen.com/books/quality-assurance-and-management/critical-success-factors-for-qualityassurance-in-healthcare-organisations.

[45] Saunders, C. (2014). Introduction to Research and Research Methods. Bradford: University of Bradford.

[46] Savedoff, W. (2007). What Should a Country Spend on Health Care? Health Affairs, 26(4), 962-970 https://doi.org/10.1377/hlthaff.26.4.962.

[47] Sial, A., Usman, M. K., Zufiqar, S., Satti, A. M., \& Khursheed, I. (2013). Why Do Public Sector Organisations Fail In Implementation of Strategic Plan in Pakistan? Public Policy and Adminstration Research, 3(1), 222-573.

[48] Thompson, J. M., Buchbinder, S. B., \& Shanks, N. H. (2012). An overview of healthcare management. In S. B. Buchbinder, \& N. H. Shanks, Introduction to Health Care Management (pp. 1-16). Jones and Bartlett Inc.

[49] Vaidya, K., Sajeev, A. S., \& Callender, G. (2006). Critical Factors That Influence E-Procurement Implementation Success in The Public Sector. Journal of Public Procurement, 6(1\&3), 70-99.

[50] Webster, T. R., Mantopoulos, J., Jackson, E., Cole-Lewis, H., Kidane, L., Kebede, S., Bradley, E. H. (2011, April 30). A brief questionnaire for assessing patient healthcare experiences in low-income settings. International Journal of Quality Health Care, 23(3), 258-268. https://doi.org/10.1093/intqhc/mzr019.

[51] Wegner, T. (2010). Applied Business Statistics: Methods and Excelbased Applications. Cape Town, South Africa: Juta \& Co. Ltd.

[52] Welman, C., Kruger, F., \& Mitchell, B. (2010). Research Methodology. South Africa: Oxford

[53] WHO. (2010). The World Health Report 2010 - Health Systems:Improving Performance. Geneva: World Health Organization (WHO).

[54] World Bank. (2010, May 22). Namibia Health Sector Note (P110113). Health, Nutrition and Population, Southern Africa Country Department I. Washington D.C: World Bank.

[55] Yang, L., Guohui, S., \& Eppler, M. J. (2008). Making Strategy Work: A Literature Review on the Factors influencing Strategy Implementation. ICA Working Paper 2. Institute of Corporate Communication.

[56] Zikmund, W. G., \& Babin, B. J. (2010). Essentials Of Marketing Research (4th ed.). Mason,OH: South-Western, Cengege Learning. 